\title{
Differentiation of paediatric burn injury by household energy source in South Africa
}

\author{
Rajen Govender ${ }^{1,2,3 *}$, David Kimemia1, Nancy Hornsby ${ }^{1}$, Ashley Van Niekerk1 \\ 1 Institute for Social and Health Sciences, University of South Africa, P.O. Box 1087, Lenasia 1820, South Africa. \\ 2 Department of Sociology, University of Cape Town, Rondebosch, Cape Town, South Africa \\ 3 Violence, Injury and Peace Research Unit, South African Medical Research Council, P.O. Box 19070, \\ Tygerberg 7505, South Africa. \\ ORCiDs:
}

Rajen Govender: https://orcid.org/0000-0003-2720-7653

David Kimemia: https://orcid.org/0000-0002-5790-8541

Nancy Hornsby: https://orcid.org/0000-0001-5625-0306

Ashley van Niekerk: https://orcid.org/0000-0003-2900-8519

\begin{abstract}
Burn injuries remain a significant cause of death and disability in the global south, with children amongst the most vulnerable. In South Africa, burns are a critical health and economic burden in densely populated and energy-impoverished communities. This study used secondary data on burn injuries from 19 health facilities to differentiate between risk for scalds and flame burns across three household energy sources (firewood, paraffin and electricity). The sample was 2933 cases of child burn victims, with key analytical procedures being descriptive statistics and logistic regression analysis. Results showed that $52 \%$ of burn injury admissions reported electricity as the household energy source used at the time of injury. Most burn injuries were scalds (85.3\%), with infants and toddlers at greatest risk. The differentiation between wood and paraffin was associated with a threefold increase in scalds relative to flame burns, while that between paraffin and electricity indicated a sevenfold increase in scalds and nineteen times such an increase between wood and electricity. This was an indication of continued challenges for the country in addressing paediatric burns despite, and in the context of, the continued electrification of poor households. The study recommends improved regulation of electrical appliances used by lowincome households, and targeted household safety education initiatives.
\end{abstract}

Keywords: child burns, domestic energy-use, electrification, energisation

Highlights:

- Study differentiated the risk for scalds versus flame burns across fuels.

- Most burn injuries were scalds, with toddlers at greatest risk.

- Electricity was associated with most scalds relative to wood and paraffin.

- Regulation of simple electrical appliances and safety education is recommended.

Journal of Energy in Southern Africa 31(2): 48-58

DOI: http://dx.doi.org/10.17159/2413-3051/2020/v31i2a8096

This work is licensed under a Creative Commons Attribution-ShareAlike 4.0 International Licence Published by the Energy Research Centre, University of Cape Town ISSN: 2413-3051 https://journals. assaf.org.za/jesa

Sponsored by the Department of Science and Technology

* Corresponding author: Tel: +27 83576 6816;

email: govender@iafrica.com 


\section{Introduction}

The establishment of democracy in South Africa in 1994 heralded a significant transition in the energy and electricity environment of the country. During apartheid rule the country was characterised by an energy-intensive economy serviced by a stable single electricity provider with substantial reserve margins after a protracted period of intensive capacity development (Marquard et al., 2007). Despite this, by the start of the transition from apartheid to democracy in 1990, it was estimated that about two thirds of all households in the country were not electrified. The election in 1994 of the new democratic government ushered in several significant changes to both the national institutional and policy landscape, and these had a profound impact on the electricity environment and household energy use. The new government developed a comprehensive overarching development agenda in the form of the Reconstruction and Development Programme (RDP), which was intended to redress historical injustices and ensure equitable access to modern services (African National Congress, 1994). Electricity formed a central component of these modern services. The RDP regarded the electrification programme as central to promoting the overall health, welfare and well-being of the population. Accordingly, it prioritised the expansion of the national electrification programme, establishing the Integrated National Electrification Programme (Tinto and Banda, 2005). The RDP set the goal of connecting a further 2.5 million households to the national grid by 2000, an effective doubling of the number of connected households from 1990. The electrification project was fortified by the White Paper on energy policy, which declared that household access to adequate energy services for cooking, lighting and communication is a basic need' (Department of Minerals and Energy (DME), 1998). The policy paper further affirmed that, while this need can be met in households by 'various fuel-appliance combinations, government recognises that without access to electricity ... human development potential is ultimately constrained' (DME, 1998).

Following on from the White Paper, the policy, legislative and institutional landscape in the country was sufficiently transformed to ensure accelerated delivery of electricity to households. In 2003, the government promulgated a free basic electricity (FBE) policy to enable electricity consumption in indigent households (DME, 2003a). The FBE provided about $50 \mathrm{kWh}$ of free electricity per household per month. Despite the salutary intention, this policy had a few shortcomings. One of these was failure to regulate and provide access to safe and efficient electrical appliances, resulting in the newly electrified households acquiring substandard stoves and heaters, which flooded the market at that time and many of which were inherently risky. The FBE policy also distorted the energy choices of poor households by positioning electricity as the panacea for all domestic energy needs, whereas alternatives such as liquefied petroleum gas could deliver a similar service, especially for cooking, at a lower cost (Howells et al., 2006).

Taken together, the collective outcome of the various policy and legislative initiatives in the period from 1990 to 2003 was to firmly establish the putative relationship between electrification and human development in the country. Energy services provided by electricity were considered foundational to improving the overall well-being of poor households through the use of modern devices for household work, study and recreation; and reduced exposure to health damaging pollutants, burns and poisonings (Barron, 2017). In addition, electrification was expected to boost economic development through use of mechanical energy and reduced need for labour-intensive fuel collection chores (Haines, 2007). Within five years of the accelerated electrification drive (1994 to 1999), about 2.8 million households were added to the national grid (Ziramba, 2008), surpassing the initial target. The percentage of South African households connected to electricity further increased from $77.1 \%$ in 2002 to $85.5 \%$ in 2015 (Statistics South Africa, 2015). Concurrently, the percentage of households that used paraffin declined from $16.2 \%$ in 2002 to $5.4 \%$ in 2015 , while the percentage of households that used firewood decreased from 19.3\% to 9.3\% (Ntsoko, 2016). Based on these statistics, the greater electrification undoubtedly reduced the use of smoky fuels and flame-based light sources, thereby promoting overall health and wellbeing. Of interest in this article is the impact of electrification on community health, specifically on the occurrence of paediatric burns, which are considered a sensitive health and safety indicator of domestic energy usage (Kimemia \& Van Niekerk, 2017; Van Niekerk et al., 2006).

\subsection{Household energy transition}

Energy transitions broadly refer to a change in terms of quantity and quality from one state of an energy system to another state (Araujo, 2014). The sociotechnical, economic and political dynamics of respective epochs and location influence the nature and manner of energy transition. Generally, energy transitions occur from biomass to fossil fuels to electric current, and each successive transition is expected to 
lead to improvements in health, safety and overall wellbeing of the population. Where wood is harvested from woodlots, a move to refined fossil fuels such as paraffin or gas generally reduces labour effort and drudgery (Barnes et al., 2014). A further progression to the use of electricity in the household for multiple tasks implies even better utility and diverse socioeconomic and health benefits. It is incumbent upon countries to provide adequate, affordable and reliable energy for their citizens.

The quality of the energy matters, the universal desire being to adopt cleaner, safer and higher energy density sources, as well as more efficient and safe conversion technologies (Lambe et al., 2015). Energy transition management requires a conscious effort to guide the transitions along desirable pathways (Meadowcroft, 2009). Transition management should arguably focus on energisation, as opposed to straightforward electrification (Ramakimar, 1996). Energisation in this case refers to the use of available energy resources in an integrated fashion with proper resourceneed matching. Although the South African White Paper on Renewable Energy (DME, 2003b) conceptualised the electrification programme as part of energisation, the focus remained overwhelmingly on electrification and largely exclusive of other energy sources (Gaunt, 2003). Unlike electrification, the energisation approach has better prospects for a society-wide transition to modern energy and the attainment of sustainable development, poverty alleviation and better health and safety outcomes. Within the household energy sector, people are not after energy per se, but the fundamental tasks performed with energy, such as cooking, lighting, heating, cooling and production. Modernisation of the energy system, which occurs through energy transition, should ideally assure the availability of these energy services in a safer and more efficient manner. Better educated populations and interventions around behavioural change may positively influence the transition to modern energy. Even though most routine forms of energy use and energy transitions involve complex behavioural, cognitive, and social processes (Kowsari and Zerriffi, 2011), this human dimension of energy use has been and continues to be largely overlooked in energy access programmes (Laitner, 2007).

\subsection{Persisting health burdens from household- energy use in South Africa}

South Africa has reported a range of ongoing health losses attributed to its energy usage, e.g., through exposure to household air pollution from coal and biomass combustion (Barnes et al., 2009), burn injuries (Kimemia and Van Niekerk, 2017), and paraffin poisonings (Schwebel et al., 2009). Household air pollution is a widely recognised phenomenon in developing countries that rely on biomass and traditional fuels (World Health Organisation (WHO), 2016). In this case, better access to electricity and cleaner fuels is often viewed and pursued as the most rational solution (International Energy Agency, 2016). However, the persisting burn burden in transitional developmental states, such as South Africa, is a cause of concern, yet is generally overlooked in Global Burden of Disease (GBD) studies and energy access policies (Kimemia et al., 2014). Globally, mortality from burns was estimated at 180000 in 2017 (WHO, 2017), with mortality from fire having significantly reduced in recent years, from 299 600 in 1990 to about 237000 in 2013 (GBD, 2013). Mortality and morbidity from burns are strongly associated with poverty, with higher incidence of burns among children in low- and middle-income countries, and with poorer families in high-income countries (Rybarczyk et al., 2017; United National Children's Education Fund 2004). Most of the childhood burns occur at home (Ayoub et al., 2017), in sites characterised by overcrowding, dangerous cooking practices, improper use of paraffin, and uneven safety practices or awareness (Dhopte et al., 2017). Burn injuries account for the longest stay of all hospital admissions for injuries, thus raising treatment costs (Toon et al., 2011), in addition to indirect costs from long-term trauma and lost earnings in the case of adults.

Circumstances of occurrence, the contribution of neighbourhood poverty and housing conditions, and perspectives on the aetiology and prevention describe South Africa's burn injury burden, according to Van Niekerk et al. (2012) and Van Niekerk et al. (2017). These studies indicate that thermal injuries are the most common external cause of death for persons under the age of four years and the third most common cause of injury fatality for persons under the age of eighteen. Furthermore, about $3 \%$ of South Africans suffer thermal injuries annually, with about $20 \%$ of these being moderate-to-serious burns that require specialised treatment (Rode et al., 2011). Other studies have provided initial information on the likely relationship between different energy types and the propensity and relative risks of burn injuries (Kimemia et al., 2014; Gevaart-Durkin et al., 2014).

The present study located itself in this area through a statistical analysis of a national hospital dataset on burn injuries. It differentiated between risk for scald and flame burn across 
three main energy source types, i.e., wood, paraffin and electricity, amongst South African child burn victims. This analysis was used to examine whether the risk for different types of burn injuries varies with energy source types, the nature of these changes, and the reasons for them. The objective was to provide greater clarity on how the energy transition from biomass and fossil fuels to electricity may have impacted South African community health, as measured by paediatric burn risk.

\section{Methodology}

The dataset included 19 health institutions at regional or provincial level. These key health facilities mostly service densely populated, lowincome settlements that are highly indicated for burn incidents (Gevaart-Durkin et al., 2014). The hospitals are distributed in eight South African provinces, and clustered around major metropolitan areas and secondary cities. The study used secondary data related to burn injuries recorded from May 2006 to November 2012 at these hospitals, with details on the cause, type and circumstances associated with injuries from each domestic energy-use related hospital admission. The data was accessed in 2012 from the Household Energy-Related Morbidity and Mortality Surveillance database managed by the Paraffin Safety Association of Southern Africa (PASASA). Primary data was collected by means of first-language interviews with patients or caregivers, and a review of hospital records. No names or any form of personal information were used that could identify participants. Verbal informed consent was obtained, given the low literacy levels of the sample. The captured patient data was entered on the Household Energy-Related Morbidity and Mortality Surveillance Data Form. Burn injuries were categorised following the Inter-national Classification of Diseases-9 convention. The dataset comprised 12079 cases with details on the cause and type of burn injuries from each domestic energy-use related hospital admission. The current analysis focused on a paediatric sample between the ages of 0 and 12 years, a total of 2933 cases. The study was cleared by the Health Research Ethics Committee of the South African Medical Research Council.

Descriptive statistics and logistic regression analysis were used to examine key sample characteristics and risk for burn injury across a series of control and key explanatory factors. A significance level was used to report statistically significant findings, where $\mathrm{p}$ is defined as the strength of evidence in support of the null hypothesis. The analysis was performed using the Statistical Package for Social Sciences version 25.

\subsection{Antecedent factors}

Incident season, incident weekday, incident time of day, burn severity, and energy source were entered as key explanatory variables in the logistic regression analysis. Risk for burn injury is known to be influenced by seasonality and temporality with certain months and weekday periods associated with a higher risk for burn injury (Alnababtah et al., 2011). In addition, the type of energy source used may influence the incidence and severity of thermal burns ( Kagan et al., 2013).

\subsection{Outcome measures}

Type of burn injury was used to assess risk for burn injury, which comprised two categories, scalds and flame burns. Other burn categories present in the data such as electrical and gas burns had too few cases and were therefore excluded from the analysis.

\section{Results}

\subsection{Descriptive statistics}

The sample comprised slightly fewer females (43.1\%) than males (56.9\%). The average age was 2.94 years. Scalds accounted for $85.3 \%$ of burn injuries, with most burn injuries being first degree (50.9\%), followed by second degree (42.9\%) and third degree (6.2\%). Most burn injuries occurred during the cold to cool months (51.0\%), during weekdays (60.4\%) and in the mornings 6-11 am (38.8\%). Overall, the highest proportion of burns were caused by electricity (52.2\%), followed by paraffin (41.1\%) (Table 1).

When burn injury type was differentiated across energy source, the highest proportions of scalding occurred with electricity (72.1\%), followed by paraffin (22.1\%) and firewood (5.8\%). Figure 1 shows that flame burns (unadjusted) were highest when paraffin was the energy source (49.5\%), followed by electricity (27.1\%) and then firewood (23.3\%).

\subsection{Multivariate analysis}

Logistic regression analysis was performed with burn injury (scald vs flame burns) as the dependent variable and incident season, day of the week, time of day, burn severity and energy source as key explanatory variables. Gender, race and age were included as control variables.

Burn injury risk was assessed to establish whether the risk for scalds versus flame burn injuries was differentiated by the energy source involved in the burn incident. Flame burn injury was set as the reference category. The overall model was statistically significant: $\left(\chi^{2}=239.01\right.$, $\mathrm{df}=16, \mathrm{p}=0.00$ ), indicating a good fit for the 
Table 1: Sample descriptive characteristics.

\begin{tabular}{|c|c|c|}
\hline & Number & $\%$ \\
\hline \multicolumn{3}{|l|}{ Gender } \\
\hline Females & 1275 & 43.1 \\
\hline Males & 1681 & 56.9 \\
\hline$\overline{\text { Mean age (SD) }}$ & $2.94(3.03)$ & \\
\hline \multicolumn{3}{|l|}{ Age } \\
\hline$<1$ year & 369 & 12.3 \\
\hline 1 year & 932 & 31.1 \\
\hline 2 years & 576 & 19.2 \\
\hline 3 years & 306 & 10.2 \\
\hline 4-5 years & 301 & 10.1 \\
\hline $6-12$ years & 509 & 17.0 \\
\hline \multicolumn{3}{|l|}{ Burn injury } \\
\hline Scalds & 1840 & 85.3 \\
\hline Flame burns & 317 & 14.7 \\
\hline \multicolumn{3}{|l|}{ Burn severity } \\
\hline First degree & 1143 & 50.9 \\
\hline Second degree & 963 & 42.9 \\
\hline Third degree & 138 & 6.2 \\
\hline \multicolumn{3}{|l|}{ Incident season } \\
\hline Cool to cold months & 1459 & 51.0 \\
\hline Warm to hot months & 1402 & 49.0 \\
\hline \multicolumn{3}{|l|}{ Incident weekday } \\
\hline Weekday & 1727 & 60.4 \\
\hline Weekend & 1134 & 39.6 \\
\hline \multicolumn{3}{|l|}{ Incident time of day } \\
\hline Early morning (0-5am) & 195 & 8.0 \\
\hline Morning (6-11am) & 950 & 38.8 \\
\hline Afternoon (12-5pm) & 755 & 30.8 \\
\hline Evening (6-11pm) & 550 & 22.5 \\
\hline \multicolumn{3}{|l|}{ Energy source } \\
\hline Electricity & 1561 & 52.2 \\
\hline Paraffin & 1231 & 41.1 \\
\hline Firewood & 201 & 6.7 \\
\hline
\end{tabular}

explanatory variables in differentiating the likelihood of scalds from flame burns in the paediatric sample $\left(\chi^{2}\right.$ represents the test of goodness of fit of the regression model and df represents the overall degrees of freedom in the model). Younger children aged $<1$ year $(\mathrm{OR}=2.24 \%$, 95\% CI [1.13-4.45]) and 1 year (OR = 2.08, 95\% CI [1.25-3.46]), were significantly more likely than older children (6-12 years) to suffer scald injuries as compared with flame burns (OR and $\mathrm{CI}$ are respectively the Odds Ratios and the Confidence Interval for the odds ratios) (see Table 2).

Seasonal, temporal and burn severity factors Scalds were less likely to take place during the cold season (OR $=0.62$, 95\% CI [0.43-0.89]) compared with flame burns. There were no differences in risk of burn injury by time of day. Compared with flame burns, scalds were about $50 \%$ less likely to be third degree rather than first degree burns (OR $=0.52$, 95\% CI [0.280.95] (Table 2).

\section{Burn injury risk differentiation by energy source}

Burn injuries were almost 19 times more likely to be caused by scalds than flame burns (OR = 18.29, 95\% CI [11.27-29.69], in cases where the energy source was electricity, but not firewood. Scalding burn injuries were almost three times more likely than flame burns when the energy source was paraffin as compared with firewood (OR $=2.87,95 \%$ CI [1.81-4.55]. Equally, the likelihood for scalds was almost seven times higher than for flame burns when the energy source was electricity as opposed to paraffin $(\mathrm{OR}=$ 6.67, 95\% CI [4.42-10.08].

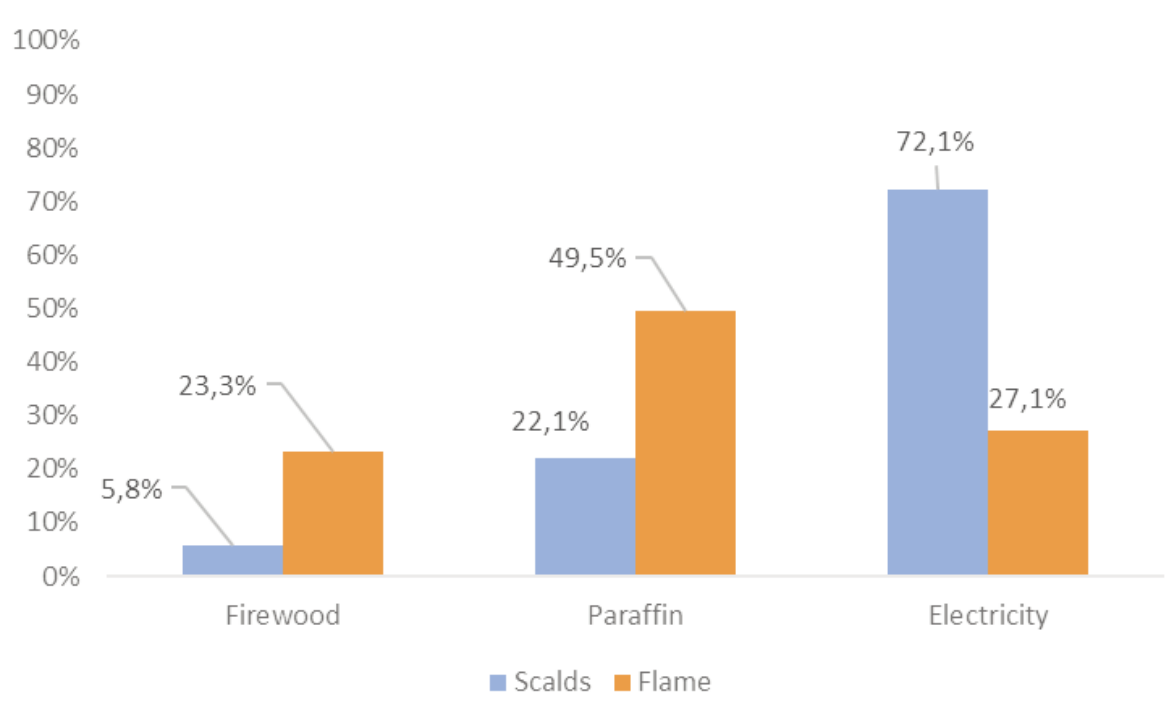

Figure 1: Scald versus flame burn injury by energy source. 
Table 2: Logistic regression examining differences across scalds and flame burns.

\begin{tabular}{|c|c|c|}
\hline & $\mathrm{OR}^{\mathrm{a}}$ & $95 \% \mathrm{CI}^{\mathrm{b}}$ \\
\hline \multicolumn{3}{|l|}{ Gender } \\
\hline Female & 1.11 & $0.78-1.59$ \\
\hline Male ${ }^{c}$ & . & . \\
\hline \multicolumn{3}{|l|}{ Age } \\
\hline$<1$ year & $2.24^{* * *}$ & $1.13-4.45$ \\
\hline 1 year & $2.08^{* * *}$ & $1.25-3.46$ \\
\hline 2 years & 1.14 & $0.68-1.93$ \\
\hline 3 years & 1.07 & $0.59-1.94$ \\
\hline 4-5 years & 1.35 & $0.71-2.54$ \\
\hline $6-12$ years ${ }^{c}$ & . & . \\
\hline \multicolumn{3}{|l|}{ Incident season } \\
\hline Cold & $0.62^{* * *}$ & $0.43-0.89$ \\
\hline Hot ${ }^{c}$ & . & . \\
\hline \multicolumn{3}{|l|}{ Incident weekday } \\
\hline Weekday & 1.33 & $0.92-1.98$ \\
\hline Weekend ${ }^{\mathrm{c}}$ & . & . \\
\hline \multicolumn{3}{|l|}{ Incident time of day } \\
\hline Early morning (0-5am) & 1.16 & $0.60-2.21$ \\
\hline Morning (6-11am) & 1.54 & $0.96-2.44$ \\
\hline Afternoon (12-5pm) & 1.36 & $0.83-2.24$ \\
\hline Evening $(6-11 \mathrm{pm})^{c}$ & . & . \\
\hline \multicolumn{3}{|l|}{ Burn severity } \\
\hline Third degree & $0.52^{* * *}$ & $0.28-0.95$ \\
\hline Second degree & 1.01 & $0.69-1.46$ \\
\hline First degree $^{c}$ & . & . \\
\hline \multicolumn{3}{|l|}{ Energy source } \\
\hline Electricity & $18.29 * * * *$ & $11.27-29.69$ \\
\hline Paraffin & $2.87^{* * * * *}$ & $1.81-4.55$ \\
\hline Firewood ${ }^{c}$ & . & . \\
\hline \multicolumn{3}{|c|}{$\begin{array}{l}\text { Reference category for the dependent variable is flame } \\
\text { burns. } \\
\text { a Odds ratio; b 95\% Confidence interval; } \\
{ }^{\mathrm{c}} \text { Reference category } \\
{ }^{*} \mathrm{p}<0.10 \text {; }{ }^{* * *} \mathrm{p}<0.05 ;{ }^{* * * * *} \mathrm{p}<0.01\end{array}$} \\
\hline
\end{tabular}

\section{Discussion}

The study has highlighted that even though household energy may have shifted from low quality fuels to those with higher energy densities and more power, this may not have necessarily translated to safety improvements for household members. This raises the need to factor safety considerations in energy access programmes, such as South Africa's integrated national electrification programme, especially in the context of the prevailing paediatric burn burden. Keeping all other identified variables constant, the study shows that the use of electricity is associated with a significantly greater increase than firewood in scalding injuries relative to flame injuries. Similarly, the use of paraf- fin rather than firewood is associated with a significant increase in the risk for injury from scalding, compared with flame burns. The increase in scalds relative to flame injuries in the comparison of electricity with either firewood or paraffin is unsurprising, given that in both instances the progression signals a move away from the risks associated with exposure to the naked flame. What is perhaps unexpected is the magnitude of the observed increase and the fact that even the differentiation between paraffin and firewood is also associated with increased scalding risks. The observed increase in the risk of burn injuries from scalds as compared with flame burns when a household transitions away from combustion fuels to electricity may be explained by the increased boiling and cooking opportunities, likely complacency on safety in adoption of electricity, and the leapfrogged electrification drives that are conducted without prudent investments in safety education and safe and efficient conversion technologies. For all these reasons, households that are transitioning to modern energy may experience greater vulnerability than those which do not. The next sections expound on these reasons, focusing especially on the vulnerability of paediatric burn victims in under-resourced and spatially constrained homes.

\subsection{Fuel differentiation and increased boiling and cooking opportunities}

Although the proportion of flame injuries decreased when paraffin is compared with electricity, this proportion increased when paraffin is compared with firewood. One explanation would relate to the greater energy density of paraffin and the ease of igniting and operating a paraffin stove as compared with the use of firewood, which significantly increased the risk for all types of burn injuries (Kimemia and Van Niekerk, 2017; Parbhoo et al., 2010). Furthermore, this greater ease of ignition and use arguably increases the household production of hot liquids, which then further contribute to an increased risk, specifically for scalding.

Similarly, just as paraffin use increases the ready availability of hot liquids over the use of only firewood, electricity increases this so much further, given the rapidity and ease with which water, food or other liquids may be boiled on a stove or by kettle (Drago, 2005). Electricity also presents greater exposure to scalding, given that hot water may also be produced directly and on demand from the taps where geysers are present in the household (Lu and Katipamula, 2005; Boait et al., 2012). The increased scalding risk would also be further compounded by at least initial caregiver unfamiliarity with new 
paraffin or electrical appliances (Van Niekerk et al., 2017), and the limited stability of common stove and pot combinations, the risks of which may be underestimated (Kimemia and Van Niekerk, 2017). This lack of knowledge on how to use the paraffin or electrical appliance safely - including an inability to estimate task performance time, the temperature of pot or stove handles, or the temperature of the heated liquids - may contribute to a greater risk of scalding relative to flame burns (Van Niekerk et al., 2010). In such an environment, the natural curiosity but still-developing risk-appraisal capacities of children, especially infants and toddlers, puts them at risk around such stoves, with curiosity-driven attempts to touch the stove or grasp at handles resulting in spills and scalds (Schmid, 2017). There is also evidence to suggest that children are especially vulnerable to scalds from microwave ovens, as these provide no visual cues to indicate the temperature of heated liquids (Lowell, 2008). It is likely that this unfamiliarity also extends to caregivers in newly electrified households, thereby increasing the risks for children in their care.

\subsection{Safety complacency with electrification}

It may be argued that the greater risk exposure for scalds versus flame burn injuries posed by the differentiation across the energy types is compounded by a reduction in householder vigilance, with existing safety approaches, practices and behaviours being relaxed once the household transitions from firewood to either paraffin or electricity. This effect may be particularly pronounced in the case of electricity which, apart from the risk of electrocution, may be seen by householders as being intrinsically safe (Francioli, 2018; Gooday, 2008). These misperceptions of electricity as a safe energy carrier may generally persist until there are consequences in terms of morbidity or mortality (Johnson, 2018). This may explain why electricity is indicated for more burn injuries than are other sources of energy, with the majority of these being scalds (Sierra-Zuniga et al., 2013). In South Africa, households in informal settlements may have an automatic association of burn injuries with incidents involving flames, a likely representation of the accumulated individual, family or community experiences in such communities, where multiple fire occurrences are common and an issue of local concern. Such events would often be accompanied by widespread media accounts, with informal settlement fires attracting considerable public interest, given the human and environmental devastation that often accompanies such events (Clegg et al., 2007). The minimising of burn dan- gers associated with electricity may be consistent with cognitive consistency theories which assert that when people consider an activity or technology to be beneficial they may, to be consistent, also tend to view the technology as having low risk, that is, a 'halo effect' (Finucane et al., 2000). Where informal settlement fires are associated with wood or paraffin use, electrification may be readily seen as a panacea for the dangers of such events. Stated differently, there may be a heightened sensitivity and awareness to burn injury in the presence and during the use of naked flames. Once homes are electrified, and the naked flame is no longer available, or its use is greatly reduced, households may relax this heightened awareness and vigilance, thereby discounting the continued risk for burn injuries. The induced false sense of security may lead to a failure to recognise that the risk of injuries from scalds still exists and has even become considerably greater with electricity than it might have been with paraffin and firewood.

\subsection{Even greater child vulnerability}

This failure is tragically manifest in the particularly high infant scalding vulnerability indicated in this study. This is consistent with high infant and toddler scalding reported in South Africa (Van Niekerk et al., 2006) and elsewhere in Africa (Furjuoh, 2006), with recent observations that childhood scalding may even be on the increase in parts of South Africa (Wesson et al., 2013). These injuries are typically the consequence of hot beverage and food spills, and bathing incidents through hot water-tap or bathwater temperatures. This study reported all children, irrespective of age, to be at a heightened risk of scalding, although this is amplified for those aged one year and younger. The risk appraisal and behavioural capacities for younger, as opposed to older, school-going children varies. It is the younger child that has especially limited and still developing physical and cognitive vulnerabilities, with for infants an especially marked dependence on caregivers (Van Niekerk et al., 2013). Caregivers' awareness of the temperature of liquids that they may be consuming, while caring or holding children, and appraisals of the ability of a baby to reach out and grasp objects of interest, may be important, along with the adult awareness of the temperature of the liquids for the bathing or drinking by the child (Feldman et al., 1998). In general, young children are curious about their environment and have an increased but still evolving and unstable physical ability to explore it (Van Niekerk et al., 2013). Toddlers are especially prone to grabbing objects to steady themselves as they face the challenge of learning to 
walk, thereby coming into greater contact with heat sources, such as cooking pots, kettles or heating equipment (Van Niekerk et al., 2013). Young children may also be tempted to open and run the taps, and if a geyser is available this raises the risk of scalding from the hot tap without the visible cues of danger. Tap water burns account for at least $10 \%$ of all childhood scalds that require hospitalisation (Feldman et al., 1998). Young children may be taught to be conscious about the naked flame, but in newly electrified households the absence of such visual cues may amplify the risk for scalding.

\subsection{Leapfrogged electrification with limited public campaigns and awareness}

The lack of safety knowledge and behaviour of households where electricity is present may be exacerbated by the direction and focus of public safety campaigns and interventions in the country. For the most part, these have focused on identifying and addressing the threat to child morbidity because of injuries due to flames, with burn injury considered in many instances as being synonymous with flame burns. A basic principle underlying burn prevention is keep away from excessive heat' (McLoughlin, 1995), which many people may associate with visible direct heat sources, such as a naked flame. This view is in part reinforced by the graphic symbols used by most of burn prevention organisations in South Africa (e.g. South African Burn Society and Burn Foundation Southern Africa), all of which still represent the risk of burns using the symbol of a flame. As a result, the focus of safety campaigns remains directed towards poor households still using firewood and paraffin, with the aim to increase awareness and improve safety knowledge and behaviours around reduction of flame burn injuries. With the introduction of new types of energy, a focus on the changing knowledge needs of household energy users is vital to ensure consumer safety (Geels et al., 2016). South Africa's accelerated electrification programme was designed to leapfrog poor households towards using electricity for all household energy needs. The potential for leapfrogging is, however, often overstated by planners and project implementers, who have tended to focus on the technical and economic viability of proposed energy technologies, while insufficiently considering the social conditions and economic realities of daily life (Murphy, 2011). This is arguably misconceived, considering that energy transitions are evolutionary and incremental processes, not leaps, with such transitions dependent upon household accumulations of knowledge and technological capabilities. This includes the indi- vidual's capacity to acquire and adapt to new technologies and their desire to modify their behaviour (Murphy, 2011; Geels, 2002).

Furthermore, South Africa's electrification programme lacked a dedicated safety education component in the delivery model. Instead, there were episodic electricity safety campaigns that occurred tardily in areas that reported increased incidents of illegal electrification and, even then, these tended to focus overwhelmingly on the dangers of electrocution (Eskom, 2017). The focus on electrocution is admittedly critical, but it is inadequate, as it may induce households to conclude that the transition to electricity has resulted in the significant subsidence of burn risks and that the primary safety knowledge and behaviours that need to be acquired need to be redirected towards electrocution prevention. By emphasising flame burns, targeting firewood and paraffin stoves, and focusing on electrocution in the case of electricity, such campaigns may unwittingly contribute to the householder false sense of security about the overall burn risks associated with electricity. Additionally, the absence of legislation and regulations governing the production and sale of electrical appliances for low-income markets is perhaps the weakest link in the leapfrogged transition to electricity in South Africa. Poor households that are newly electrified cannot afford the sturdier and higher quality - but more expensive - electrical stoves, and therefore resort to the most cost-effective, but poorly constructed, unsteady and riskier stoves (Still et al., 1998). Apart from stoves, the burn injury risk is similarly greater for other unregulated electrical devices, such as with hot water from unregulated geysers or hot water cylinders (Rayner and Prentice, 2011).

\section{Conclusion and policy recommendations}

There is no national South African data to indicate if the absolute incidence of burn injuries has increased or decreased in the energy transition of households from firewood to paraffin to electricity; and this study makes no claim about this. Instead, what is raised is the finding that the energy differentiation is associated with a differentiation in the burn risk from flame burn to scalding and that, for the various reasons identified, poses an ongoing and possibly escalating threat to households and especially young children. Based on the foregoing, the study makes the following recommendations to address and enhance the prevention of paediatric burns in South Africa:

\section{Energisation as opposed to electrification}

A paradigm shift is needed, from an electrification to energisation approach in the transition 
to modern energy in South Africa. The energisation approach permits for an integration of different energy sources into the delivery model, guided by assessed improvements in cleanliness, safety, efficiency and sustainability. Another benefit of the energisation approach is the potential to boost local economic development by including a productive capacity in the energy delivery model. In addition, consumers have a wider choice on what to deploy for an energy task, depending on cost-effectiveness, appropriateness and availability.

\section{Electrical appliance regulations}

The South African Department of Trade and Industry should lead in the enactment of national standards to produce high quality and safe electrical appliances like stoves, kettles and heaters. The standards should be made compulsory and rigorously enforced to ensure compliance. Poor communities could be better supported with the acquisition of approved safe electrical appliances.

\section{Safety education}

Awareness education on safe use of modern energy should precede its introduction at any site, especially in poor communities. The cur- rent episodic education campaigns on fire safety and illegal electrification should be broadened to include and highlight the continued and increasing dangers of scald injuries in the context of electrification. This should be particularly targeted to recently electrified areas and sites with higher cases of burn and scald injuries.

\section{Acknowledgements}

The authors are grateful to the Household Energy Safety Association of Southern Africa for allowing access to the data and associated resources, and to the South African Medical Research Council and University of South Africa for institutional support.

\section{Author roles}

$\mathrm{RG}, \mathrm{AvN}$ and DK conceptualised the study and formulated the primary research hypotheses. $\mathrm{NH}$ oversaw data collation from the original database and $\mathrm{RG}$ and $\mathrm{NH}$ refined and cleaned the final dataset for modelling. RG performed all analyses and predictive modelling. RG, AvN and DK developed the initial framework for the manuscript. All authors were involved in interpreting findings, and writing the manuscript.

\section{References}

African National Congress. 1994. Reconstruction and development programme (RDP).

Alnababtah, K. M., Davies, P., Jackson, C. A., Ashford, R. L. and Filby, M. 2011. Burn injuries among children from a region-wide paediatric burns unit. British Journal Nursing, 20(3): 158-162.

Araujo, K. 2014. The emerging field of energy transitions: progress, challenges, and opportunities. Energy Research and Social Science, 1: 112-121.

Ayoub, A., Kosatsky, T., Smargiassi, A., Bilodeau-Bertrand, M. and Auger, N. 2017. Risk of hospitalization for fire-related burns during extreme cold weather. Environmental Research, 158: 393-398.

Barnes, B., Mathe, A. and Thomas, E. 2009. Household energy, indoor air pollution and child respiratory health in South Africa. Journal of Energy in Southern Africa, 20: 4-13.

Barnes, DF., Samad, H. and Banerjee, SG. 2014. The development impact of energy access. In Halff A, BSJR, editors. Energy poverty: global challenges and local solutions. UK: Oxford Scholarship; 2014. 54-75.

Barron, M. 2017. Household electrification and indoor air pollution. Journal of Environmental Economics and Management, 86: 81-92.

Boait, PJ., Dixon, D., Fan, A. and Stafford A. 2012. Production efficiency of hot water for domestic use. Burns, 54: 160-168.

Clegg, SK., Smith K, Cho J, Gielen A, Vernick JS. 2007. Newspaper coverage of residual fires: an opportunity for prevention communication. Injury Prevention, 13(2): 110-114.

Dhopte, A., Tiwari, B. and Bamal R. 2017. Epidemiology of paediatric burns and future prevention strategies - a study of 475 patients from a high volume burn centre in North India. Burns \& Trauma, 5: $1-8$.

Department of Minerals and Energy (DME) 1998. White Paper on the Energy Policy of the Republic of South Africa.

DME. 2003a. Electricity basic services support tariff (free basic electricity) policy.

DME. 2003b. White Paper on Renewable Policy of the Republic of South Africa.

Drago, DA. 2005. Kitchen scalds and thermal burns in children five years and younger. Pediatrics, 115(1): $10-16$. 
Eskom. 2017. Electricity safety month launched - keeping your community and children safe; 2017. Available from: http://www/eskom.co.za/news/Pages/Augg1.aspx

Feldman, KW., Schaller, RT., Feldman, JA. and McMillon, M. 1998. Tap water scald burns in children. Injury Prevention, 4: 238-242.

Finucane, ML., Alhakami, A., Slovic, P. and Johnson, SM. 2000. The affect heuristic in judgments of risks and benefits. Journal of Behavioural Decision Making, 13: 1-17.

Francioli, AP. 2018. Investigating energy usage among low income households and implications for fire risk. Master of Philosophy in Distaste Risk Science and Development Research thesis, Stellenbosch University.

Furjuoh, SN. 2006. Burns in low- and middle-income countries: a review of available literature on descriptive epidemiology, risk factors, treatment, and prevention. Burns, 32(5): 529-537.

Gaunt, C. 2003. Electrification technology and processes to meet economic and social objectives in Southern Africa. Unpublished doctoral thesis, University of Cape Town. 2003.

Global Burden of Disease Study (GBD) 2013. Mortality \& Causes of Death Collaborators. 2014. Global, regional and national age-specific all-cause and cause-specific mortality for 240 causes of death, 1990-2013. The Lancet, 385: 117-171.

Geels, F. 2002. Technological transitions as evolutionary reconfiguration processes: a multi-level perspective and case study. Research Policy, 31(8/9): 257-1274.

Geels, F., Kern, F., Fuchs, G., Hinderer, N, Kungl, G., Mylan, J., et al. 2016. The enactment of socio-technical transition pathways: a reformulated typology and a comparative multi-level analysis of the German and UK low-carbon electricity transitions (1990-2014). Research Policy, 45(4): 896-913.

Gevaart-Durkin, A., Swart, D. and Chowdhury, Z. 2014. A study of energy-related injuries from hospital admissions among children and adults in South Africa. Burns, 40: 1209-1218.

Gooday, G. 2018. Domesticating electricity: technology, uncertainty and gender London: Routledge; 2008.

Haines, F., Smith, KR. and Anderson, D. 2007. Policies for accelerating access to clean energy, improving health, advancing development, and mitigating climate change. The Lancet, 370(9594): 12641281.

Howells, M., Victor, DG. and Gaunt T. 2006. Beyond free electricity: the costs of electric cooking in poor households and a market-friendly alternative. Energy Policy, 34: 3351-3358.

International Energy Agency (IEA). 2016. World energy outlook: the world's energy needs to continue to grow, but many millions are left behind; 2016. Available from: https://www/iea.org/Textbase/npsum/WEO2016SUM.pdf .

Johnson, D. 2018. Electrical risks lack respect. Available from: https://www.ishn.com/articles/97058electrical-risks-lack-respect.

Kagan, RJ., Peck, MD., Ahrenholz, DH., Hickerson, WL., Holmes J., Korentager, R., et al. 2013. Surgical management of the burn wound and use of skin substitutes: an expert panel white paper. Journal of Burn Care Research, 34: e60-79. doi: 10.1097/BCR.0b013e31827039a6.

Kimemia, D. and Van Niekerk, A. 2017. Energy poverty. shack fires and childhood burns. South African Medical Journal, 107(4): 289-291.

Kimemia, D., Vermaak, C., Pachauri, S. and Rhodes B. 2014. Burns, scalds and poisoning from household energy use in South Africa: are the energy poor at greater risk? Energy for Sustainable Development, 18: $1-8$

Kowsari, R. and Zerriffi H. 2011. Three-dimensional energy profile: a conceptual framework for assessing household energy use. Energy Policy, 39: 7505-7517.

Laitner, J. A. 2007. The contribution of the social sciences to the energy challenge. Washington: American Council for an Energy-Efficient Economy, ACEE.

Lambe, F., Jurisoo, M., Wanjiru, H. and Senyagwa J. 2015. Bringing clean. safe, affordable cooking energy to households across Africa: an agenda for action. New Climate Economy working paper, based on a background paper to the Africa Progress Panel 2015 report Power, People, Planet: Seizing Africa's Energy and Climate Opportunities.

Lowell, G., Quinlan, K. and Gottlieb, L. 2008. Preventing unintentional scald burns: moving beyond tap water. Pediatrics, 122(4): 799-804.

Lu, N. and Katipamula, S. 2005. Control strategies of thermostatically controlled appliances in a competitive electricity market. In IEEE Power Engineering Society General Meeting, 202-207.

Marquard, A., Bekker, B., Eberhard, A. and Gaunt, T. 2007. South Africa's electrification project: An overview and assessment (Working Paper).

McLoughlin, E. 1995. A simple guide to burn prevention. Burns, 21(3): 226-229. 
Meadowcroft, J. 2009. What about the politics? Sustainable development, transition management, and long-term energy transitions. Policy Science, 42: 323-340.

Murphy, J. T. 2001. The energy transition in rural east Africa: is leapfrogging and alternative? Technological Forecasting and Social Change, 68(2): 173-193.

Ntsoko, L. Statistics on electrification in South Africa; 2016 [cited 2018 June 28]. Available from: http://www.ee.co.za/article/department-energy-acknowledges-results-statssa-electrification.html.

Parbhoo, A., Louw, QA. and Grimmer-Somers, K. 2010. Burn prevention programs for children in developing countries require urgent attention: a targeted literature review. Burns, 36: 164-175.

Ramakimar, R. 1996. Energizing rural areas of developing countries using IRES. In IECEC 96 Proc 31st Intersociety Energy Conversion Engineering Conference, 1536-1541.

Rayner, R. and Prentice, J. 2011. Paediatric burns: a brief global review. Wound Practice \& Research. 2011; 19(1): 39-46.

Rode, H., Berg, M. and Rogers A. Burn care in South Africa. 2011. Annals of Burns and Fire Disasters, 25: 7-8.

Rybarczyk, M. M., Schafer, JM., Elm, C. M., Sarvepalli, S., Vaswani, PA., Balhara, K. S., Carlson, L.C. and Jacquet, G.A.. 2017. A systematic review of burn injuries in low- and middle-income countries: epidemiology in the WHO-defined African region. African Journal of Emergency Medicine, 7: 30-37.

Schmid, D. M. 2017. The kitchen stove: a major cause of burn and scald injuries. Available from: https://www.personalinjurylawjournal.com/burn-injuries/the-kitchen-stove-a-major-cause-of-burnand-scald-injuries/.

Schwebel, D., Swart, D., Hui, S., Simpson, J. and Hobe, P. 2009. Paraffin-related injury in low-income South African communities: knowledge, practice and perceived risk. Bulletin of the World Health Organization, 87: 700-706.

Sierra-Zuniga, F., Castro-Delgado, E., Caicedo-Caicedo, C., Merchan-Galvis, A. M. and Delgado-Noguera M. 2013. Epidemiological profile of minor and moderate burn victims at the University Hospital San Jose, Popayan, Colombia, 2000-2010. Burns, 39: 1012-1017.

Statistics South Africa. 2015. General Household Survey 2015 Statistical Release PO318. Available from: https://www.statssa.gov.za/publications/P0318/P03182015.pdf .

Still, J., Craft-Coffman, B., Law, E., Colon-Santini, J. and Grant J. 1998. Burns of children caused by electric stoves. Journal of Burn Care Rehabilitation, 19(4): 364-365.

Tinto, E. M. and Banda, K. G. 2005. The Integrated National Electrification Programme and political democracy. Journal of Energy in Southern Africa, 16(4): 26-33.

Toon, M. H., Maybauer, D. M., Arceneaux, L. L., Fraser, J. F., Meyer, W., Runge, A. and Maybauer, M.O. 2011. Children with burn injuries - assessment of trauma, neglect, violence and abuse. Journal of Injury and Violence Research, 3: 96-110.

United Nations Children's Fund (UNICEF). 2004. Children and burns. Available from: http://who.int/violence_injury_prevention/child/injury/world_report/Burns_english.pdf?ua=1.

Van Niekerk, A., Govender, R., Hornsby, N. and Swart, L. 2017. Household and caregiver characteristics and behaviours as predictors of unsafe exposure of children to paraffin appliances. Burns, 43: 866-876.

Van Niekerk, A., Menckel, E. and Laflamme, L. 2010. Barriers and enablers to the use of measures to prevent pediatric scalding in Cape Town, South Africa. Public Health Nursing, 27(3): 203-220.

Van Niekerk, A., Reimers, A. and Laflamme, L. 2006. Area characteristics and determinants of childhood burn injury in Cape Town. Public Health, 120(2): 115-124.

Van Niekerk, A., Rode, H. and Laflamme, L. 2006. Incidence and patterns of childhood burn injuries in the Western Cape, South Africa. Burns, 30(4): 341-347.

Van Niekerk, A., Titi, N., Lau, U. and Arendse N. 2012. Childhood burns in South Africa: towards evidence for prevention action and policy. In Van Niekerk A, Suffla S, Seedat M, editors. Crime, Violence and Injury in South Africa: 21st century solutions for child safety. Johannesburg: PsySSA Press; 2012. 8-22.

Wesson, H. K., Bachani, AM., Mtambeka, P., Schulman, D., Mavengere, C., Stevens, K. A., Millar, A.J.W., Hyder, A.A. and van As, A.B. 2013. Pediatric burn injuries in South Africa: a 15-year analysis of hospital data. Injury, 44: 1477-1482.

World Health Organisation (WHO). 2016. Household air pollution and health; 2016 [cited 2017 November 30]. Available from: http://www.who.int/mediacentre/factsheets/fs292/en/.

WHO. 2017. Burns; 2017. Available from: http://www.who.int/mediacentre/factsheets/fs365/en/.

Ziramba, E. 2008. The demand for residential energy in South Africa. Energy Policy, 36: 3460-3466. 